\title{
Induction of Tetraploids in Impatiens (Impatiens walleriana) and Characterization of Their Changes in Morphology and Resistance to Downy Mildew
}

\author{
Weining Wang \\ Environmental Horticulture Department, IFAS, University of Florida, Gulf \\ Coast Research and Education Center, 14625 County Road 672, Wimauma, \\ FL 33598
}

\section{Yanhong He}

Key Laboratory of Horticultural Plant Biology, Ministry of Education, College of Horticulture and Forestry Sciences, Huazhong Agricultural University, Wuhan 430070, Hubei, China

\author{
Zhe Cao and Zhanao Deng ${ }^{1}$ \\ Environmental Horticulture Department, IFAS, University of Florida, Gulf \\ Coast Research and Education Center, 14625 County Road 672, Wimauma, \\ FL 33598
}

Additional index words. colchicine, ploidy manipulation, Plasmopara obducens

\begin{abstract}
Garden impatiens (Impatiens walleriana), a very important floricultural crop in the United States, has been devastated by impatiens downy mildew (IDM) in recent years. This study was conducted to determine if induced tetraploidy could improve impatiens resistance to downy mildew. Tetraploids were induced by colchicine and confirmed by chromosome counting. Compared with diploids, induced tetraploids showed significant morphological changes, including larger and thicker leaves with larger and fewer stomata; thicker and fewer stems; larger and fewer flowers; and larger pollen grains with higher stainability. In detached leaf and in vivo inoculation assays, tetraploids exhibited improved downy mildew resistance, with lower disease severity, disease incidences, and sporangia densities. Plasmopara obducens, the causal agent of IDM, underwent a similar development process in the leaf tissue of diploids and tetraploids. These results suggest that induced tetraploidy can result in significant changes in impatiens leaf and plant morphology and can increase impatiens resistance to downy mildew to a certain extent.
\end{abstract}

Garden impatiens (I. walleriana, Balsaminaceae) has been a top-selling bedding plant in the United States, generating an estimated wholesale value of 150 million dollars in 2005 (USDA/NASS, 2006). This plant's popularity in the floriculture and landscape industries is primarily due to its wide

Received for publication 22 Mar. 2018. Accepted for publication 3 May 2018.

This study was supported by the USDA hatch project (FLA-GCC-005507), the Frederic C. Gloeckner Foundation, Inc., and the American Floral Endowment.

We thank Joyce Jones and Gail Bowman for their technical support, Yinghong Wang for germinating impatiens seeds and treating seedlings with colchicine, Dr. Aaron Palmateer for confirming the identity of Plasmopara obducens, and Gaomin Deng for reviewing this manuscript. We greatly appreciate the guidance and valuable comments that Drs. Aaron Palmateer and David Clark provided.

${ }^{1}$ Corresponding author. E-mail: zdeng@ufl.edu.
$2 n=2 x=16$, whereas New Guinea impatiens is a diploid with $2 n=2 x=32$ (Arisumi, 1973a) or 48 (Jones and Smith, 1966).

Chromosome doubling is a powerful ploidy manipulation tool for plant breeding and genetic improvement. Following chromosome doubling, autopolyploids may produce larger organs and larger amounts of biomass, have higher biological yields, show changes in anatomical structures (primarily in stomata size and density), and/or have improved ornamental values. Induced tetraploids may also show improved disease resistance. For example, tetraploid Glycine tabacina became more resistant to the leafrust fungus Phakopsora pachyrhizi (Burdon and Marshall, 1981), and tetraploid Arabidopsis thaliana accession C24 became more tolerant of the necrotrophic pathogen Botrytis cinerea (Fort, 2013). Autopolyploidization has already been proposed as a means to improve disease resistance in bananas (Hamill et al., 1992). Based on mathematical models, Oswald and Nuismer (2007) predicted that autopolyploids could be more resistant to diseases than their corresponding diploids.

Arisumi (1973b) studied the morphology and breeding behaviors of colchicine-induced polyploids in several other Impatiens species, but few reports in the literature are available regarding the effects of induced tetraploidy on the morphology of I. walleriana, and there is no information on the effects of induced tetraploidy on disease resistance in I. walleriana. In this study, tetraploids were induced and their changes in morphology and IDM resistance were investigated by comparing them with diploids.

\section{Materials and Methods}

Polyploid induction. Seeds of impatiens (I. walleriana cv. Super Elfin ${ }^{\circledR}$ Lipstick) were germinated on filter paper in $100 \times 15 \mathrm{~mm}$ petri dishes at $25^{\circ} \mathrm{C}$. Germinating seeds were treated with $0 \%$ (control), $0.05 \%, 0.10 \%$, $0.15 \%$, or $0.20 \%(\mathrm{w} / \mathrm{v})$ colchicine for $2.5 \mathrm{~d}$. Each treatment consisted of three replications with 40 seeds per replication, and the different treatments were arranged in a completely randomized design. After treatment, seeds were germinated in 20-row seeder trays (model P-SEED20; Landmark Plastic Co., Orlando, FL) $(53.8 \times 27.5 \times 3.1 \mathrm{~cm})$ filled with a commercial soilless potting mix (Fafard Germination Mix; Conrad Fafard, Inc., Agawam, MA). The seeder trays were covered with plastic lids to retain moisture and placed in a growth room at a temperature of 22 to $25^{\circ} \mathrm{C}$ and $16 \mathrm{~h}$ light $/ 8 \mathrm{~h}$ dark. After true leaves emerged, seedlings were transplanted into Todd planter flats (model TR72D; Speedling, Inc., Sun City, FL) filled with the potting mix (Fafard 3B Mix; Conrad Fafard, Inc.) and grown in a greenhouse. Subsequently, seedlings were transferred to 15.2-cm plastic containers filled with Fafard 3B Mix. A water-soluble fertilizer (SA-50; 16N-3.5P-16K; Southern Agricultural Insecticides, Inc., Palmetto, FL) was applied 
at $75 \mathrm{ppm}$ once a day until plants began flowering.

Identifying putative tetraploids. The ploidy level of colchicine-treated seedlings was determined using an Accuri C6 flow cytometer (Accuri, Ann Arbor, MI) and the procedure described by Doležel et al. (2007) and modified by Cao et al. (2014). About equal amounts of leaf tissue from the treated seedlings (potentially tetraploids) and untreated seedlings (diploids) were mixed together; after the addition of $1 \mathrm{~mL}$ of cold LB01 lysis buffer (Doležel et al., 2007), the leaf tissue was chopped using a sharp blade to release nuclei. Ploidy analysis was repeated two to three times for each plant.

Determining nuclear DNA contents. The nuclear DNA content of tetraploids (and diploids) were determined using a CyFlow ${ }^{\circledR}$ Ploidy Analyzer (Sysmex Partec GmbH, Görlitz, Germany), following the procedure described by Doležel et al. (2007) and modified by Cao et al. (2014). A piece of mature leaf (about $0.5 \times 0.5 \mathrm{~cm}^{2}$ ) was co-chopped with similarly sized pieces of rye leaf (Secale cereal cv. Daňkovské) in $1 \mathrm{~mL}$ of cold LB01 lysis buffer (Doležel et al., 2007). The rye cultivar Daňkovské was used as an internal reference, and its nuclear DNA content was $16.19 \mathrm{pg} / 2 \mathrm{C}$ (Doležel et al., 2007). The nuclear DNA content of impatiens samples was calculated as follows: 2C DNA content of impatiens samples $=$ (mean sample fluorescence peak $\div$ mean internal reference fluorescence peak) $\times 2 \mathrm{C}$ DNA content of the internal reference. For each tetraploid and diploid, at least three replications of leaf samples from different shoots were analyzed, and in each run, at least 3000 nuclei were analyzed.

Chromosome counting. Chromosome counting was performed following a protocol described by Cao et al. (2014). Briefly, root tips (about $1 \mathrm{~cm}$ in length) were excised from vigorously growing roots, pretreated in a 0.02 м 8-hydroxyquinoline solution in the dark for $4 \mathrm{~h}$, and then fixed in a fixative solution (3 methanol: 1 glacial acetic acid, $\mathrm{v} / \mathrm{v}$ ) at $4{ }^{\circ} \mathrm{C}$ for $12 \mathrm{~h}$. Fixed root tips were rinsed under running water for $1 \mathrm{~min}$ and then digested in $1 \mathrm{~N}$ hydrochloric acid at room temperature $\left(\approx 24^{\circ} \mathrm{C}\right)$ for $10 \mathrm{~min}$. The root tips were rinsed with deionized water and then stained in an acetocarmine staining solution for $3 \mathrm{~h}$. The meristematic tissue of stained root tips was squashed in a drop of acetocarmine on a glass slide.

All slides were examined under a bright field microscope (BH-2; Olympus, Tokyo, Japan). Cells with darkly stained and wellspread chromosomes were photographed under a BX41 microscope (Olympus) at $\times 1000$ magnification using an Olympus Q-Color 5 camera and the Q-imaging software (Olympus America, Inc., Melville, NY).

Morphological characterization. Three diploids and three tetraploids were characterized to reveal potential morphological differences between diploids and induced tetraploids. Diploids and tetraploids were clonally propagated by cutting. Cuttings from mature shoots were placed into the Fafard 3B potting mix in the Todd planter flats (model TR72D). All flower buds on the cuttings were removed. About 4 weeks later, rooted cuttings were transplanted to 6-inch plastic containers filled with Fafard 3B mix.

For each diploid and tetraploid, three uniform rooted cuttings were selected and used as three biological replications. Ten mature leaves were collected from each clonal plant; leaf length, width, and thickness measurements were taken from these 10 leaves. Leaf length and width were measured as the distance from the tip to the bottom of the leaf blade and the widest distance across the leaf blade, respectively. Leaf thicknesses were measured with an electronic digital caliper. Nail polish imprints were taken from the abaxial surface of mature leaves and observed under the BX41 microscope at $\times 400$ and $\times 100$ magnification for stomatal length and density. Digital images of the imprints were taken using an Olympus Q-Color 5 camera and analyzed using the Q-imaging software to measure the length and density of stomata. For each clonal plant, five leaves were sampled and for each leaf, five fields of the imprints were examined.

The number of days starting from when cuttings were first placed into the potting mix until the first flower opened was recorded as the days to flower measurement. Fully opened flowers were counted a total of four times with 10-d intervals between each

Table 1. Effects of colchicine treatment on seedling survival and tetraploid induction in Impatiens walleriana cv. Super Elfin ${ }^{\circledR}$ Lipstick.

\begin{tabular}{lccc}
\hline $\begin{array}{l}\text { Colchicine } \\
(\%)\end{array}$ & $\begin{array}{c}\text { Seedling } \\
\text { survival } \\
(\%)^{\mathrm{z}}\end{array}$ & $\begin{array}{c}\text { Tetraploid } \\
\text { impatiens induction } \\
\text { rate }(\%)^{\mathrm{y}}\end{array}$ & $\begin{array}{c}\text { Tetraploid } \\
\text { impatiens induction } \\
\text { efficiency }(\%)^{\mathrm{x}}\end{array}$ \\
\hline 0 & $100.0 \pm 0.0 \mathrm{a}^{\mathrm{w}}$ & $0.0 \pm 0.0 \mathrm{NS}$ & $0.0 \pm 0.0 \mathrm{NS}$ \\
0.05 & $16.7 \pm 8.2 \mathrm{~b}$ & $5.8 \pm 3.3$ & $1.5 \pm 1.3$ \\
0.10 & $6.7 \pm 1.7 \mathrm{~b}$ & $2.5 \pm 0.0$ & $0.2 \pm 0.04$ \\
0.15 & $4.2 \pm 3.0 \mathrm{~b}$ & $0.0 \pm 0.0$ & $0.0 \pm 0.0$ \\
0.20 & $1.7 \pm 1.7 \mathrm{~b}$ & $0.8 \pm 0.8$ & $0.04 \pm 0.04$ \\
\hline
\end{tabular}

${ }^{\mathrm{z}}$ Seedling survival $=$ the number of seedlings that produced true leaves/the total number of seeds treated. Mean values of three replications, with 40 germinating seeds per replication.

${ }^{\mathrm{y}}$ Tetraploid impatiens induction rate $=$ the number of solid tetraploids induced/the total number of seeds treated.

${ }^{\times}$Tetraploid induction efficiency $=$seedling survival $\times$tetraploid induction rate (Bouvier et al., 1994).

${ }^{\text {w}}$ Mean separation in columns by Tukey's method at $P<0.05$.

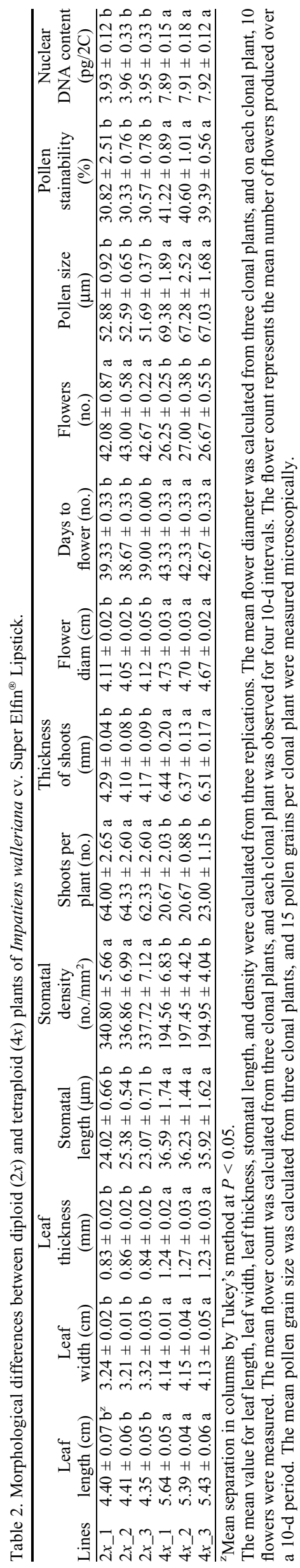

HortScience Vol. 53(7) July 2018 

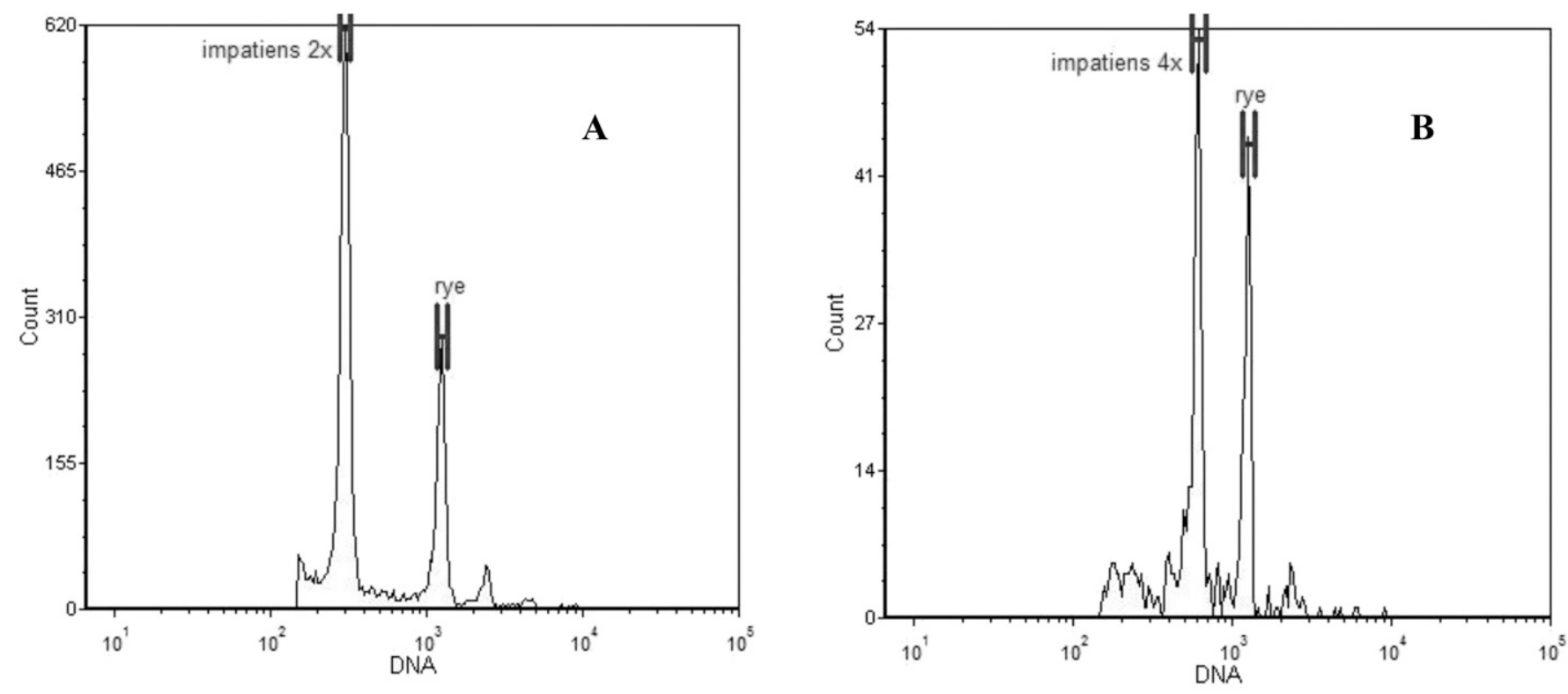

Fig. 1. Flow cytometric histograms of impatiens and rye (reference). (A) Diploid 'Super Elfin ${ }^{\circledR}$ Lipstick' impatiens and rye. (B) Tetraploid 'Super Elfin ${ }^{\circledR}$ Lipstick' and rye. The $y$-axis indicates the nuclei counts and the $x$-axis indicates the fluorescence peaks of impatiens (left) and rye (right).
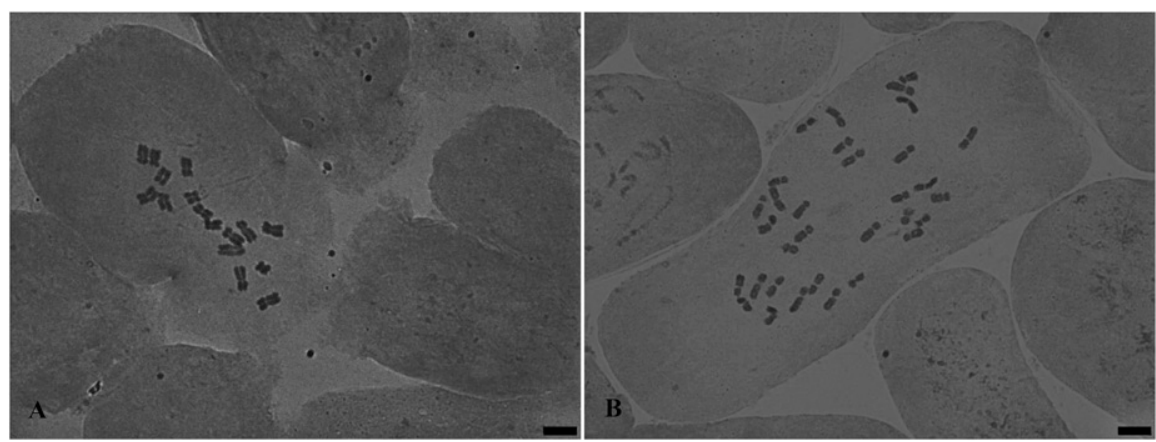

Fig. 2. Metaphase spread of 'Super Elfin ${ }^{\circledR}$ Lipstick' impatiens root tip cells. (A) Diploid cell with $2 n=2 x=16$ chromosomes. (B) Tetraploid cell with $2 n=4 x=32$ chromosomes. Bars $=5 \mu \mathrm{m}$.
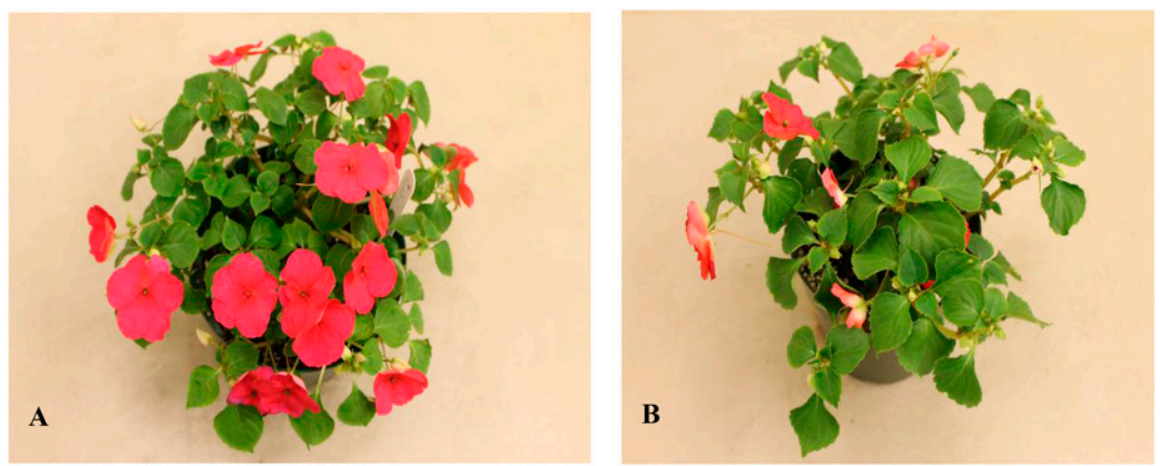

Fig. 3. Diploid (A) and induced tetraploid (B) of 'Super Elfin ${ }^{\circledR}$ Lipstick' grown in containers.

counting. These numbers were averaged to obtain the number of flowers per clonal plant. The size of flowers was measured at the widest distance between two opposite lateral petals of a fully opened flower. Ten flowers were sampled for each clonal plant and 30 flowers total for each diploid and tetraploid.

The total number of flowering shoots and the thickness of flowering shoots were used as parameters to evaluate plant architecture. The thickness of flowering shoots was measured at the midpoint of each shoot using an electronic digital caliper.

Pollen stainability was determined using the fluorochromatic procedure by HeslopHarrison and Heslop-Harrison (1970) with minor modifications. Fresh pollen grains in fully opened flowers were collected and stained with fluorescein diacetate dissolved in acetone $\left(2 \mathrm{mg} \cdot \mathrm{mL}^{-1}\right)$ and $10 \%$ sucrose. After staining at $25{ }^{\circ} \mathrm{C}$ in the dark for $1.5 \mathrm{~h}$, pollen grains were observed under a stereomicroscope (SZX16; Olympus). Pollen grains emitting green fluorescence were counted as stainable. Five flowers were sampled for each clonal plant, 15 flowers for each diploid or tetraploid, and pollen grains in three microscopic fields were examined for each flower. The length of pollen grains was measured by analyzing digital images of stained pollen grains with the Q-imaging software. Fifteen pollen grains were measured for each clonal plant and 45 pollen grains total for each diploid and tetraploid.

Determining IDM resistance. Three diploids and three tetraploids were evaluated for resistance to IDM. A single-spore isolate of $P$. obducens was obtained from IDMinfected $I$. walleriana leaves in 2014. The isolate was maintained on plants of Super Elfin ${ }^{\circledR}$ Lipstick in a growth room, as described by Ellwood et al. (2007). Two complementary resistance assays were used: leaf disc assay and in vivo inoculation assay. In the leaf disc assay, mature leaves were harvested from plants grown in the growth room and rinsed with autoclaved deionized water three times under a laminar hood. Leaf discs $(1.5 \mathrm{~cm}$ in diameter) were excised from the leaves using a cork borer and placed adaxial side up, on a $0.8 \%$ water agar plate in a $100 \times 15 \mathrm{~mm}$ plastic petri dish. Leaf discs were inoculated by pipetting $20 \mu \mathrm{L}$ of a $P$. obducens spore suspension $\left(1 \times 10^{5}\right.$ sporangia $\left./ \mathrm{mL}\right)$ onto each leaf disc. The inoculated leaf discs were left in petri dishes under the hood in the dark at $22^{\circ} \mathrm{C}$ for $24 \mathrm{~h}$ and then the droplets of the spore suspension, if still present, were blotted dry with filter paper, and the leaf discs were turned over abaxial side up. The leaf discs 

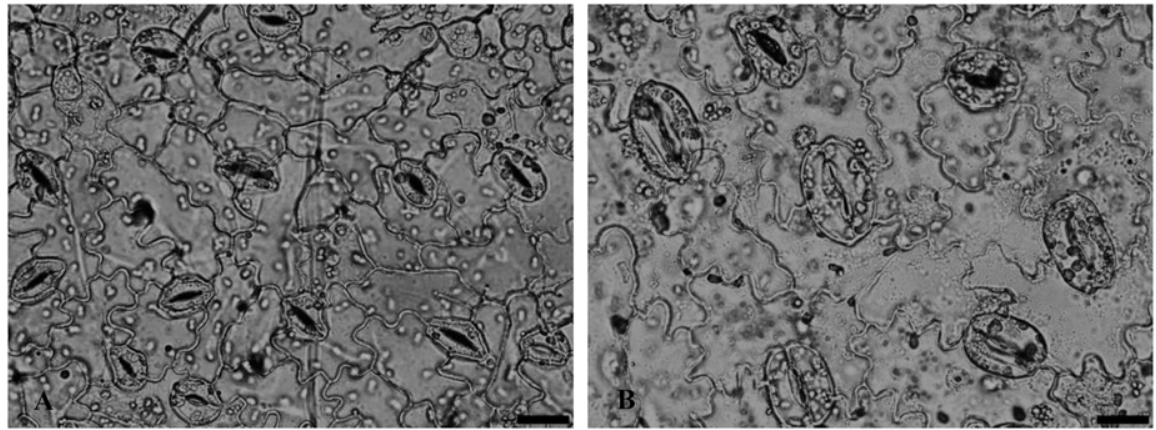

Fig. 4. Nail polish imprints taken from the abaxial surface of mature 'Super Elfin ${ }^{\circledR}$ Lipstick' leaves. (A) Diploid impatiens with a higher stomatal density and a smaller stomatal size. (B) Induced tetraploid with a lower stomatal density and a larger stomatal size. Bars $=20 \mu \mathrm{m}$.
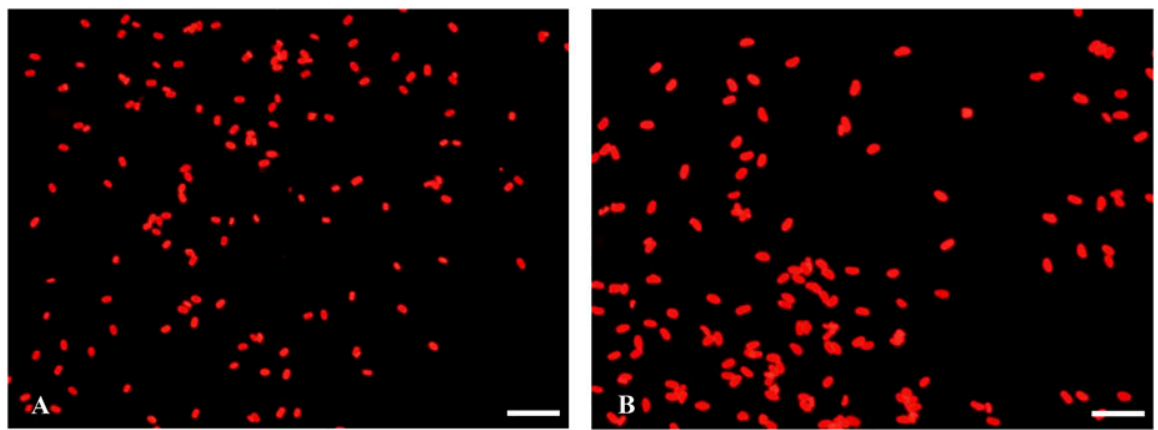

Fig. 5. Stained 'Super Elfin ${ }^{\circledR}$ Lipstick' pollen grains under a stereomicroscope. (A) Pollen grains of a diploid. (B) Pollen grains of an induced tetraploid. Bars $=250 \mu \mathrm{m}$.

were incubated at $22{ }^{\circ} \mathrm{C}$ with a photoperiod of $12 \mathrm{~h} \mathrm{light} / 12 \mathrm{~h}$ dark and a light intensity $\approx 100 \mu \mathrm{mol} \cdot \mathrm{m}^{-2} \cdot \mathrm{s}^{-1}$

Assessment of IDM severity began $6 \mathrm{~d}$ postinoculation (dpi) and ended 10 dpi. Disease severity was scored on a scale of 0 to 4 , where $0=$ no visible sporulation, and $1=1 \%$ to $25 \%, 2=26 \%$ to $50 \%, 3=51 \%$ to $75 \%$, and $4=76 \%$ to $100 \%$ of the leaf area had visible sporulation. The rating scale was modified from Brown et al. (1999). Each petri dish containing 10 leaf discs was considered as an experimental unit. For each diploid and tetraploid, at least four replications (40 leaf discs in four petri dishes) were examined at each point of time.

To determine sporangia densities on inoculated leaf discs, the leaf discs were immersed in $400 \mu \mathrm{L}$ autoclaved deionized water containing $0.05 \%$ Tween 20 in a $1.5-\mathrm{mL}$ centrifuge tube. The microcentrifuge tubes were placed on a mini-shaker (Vortex-Genie; Fisher Scientific, Waltham, MA) for 5-10 s to dislodge sporangia from leaf surfaces. About $10 \mu \mathrm{L}$ of the suspension was loaded onto a hemocytometer and observed under a BH-2 microscope (Olympus). Sporangia counting was performed at 6, 8, and $10 \mathrm{dpi}$. Two leaf disc assay experiments were conducted for the diploids and tetraploids. In each experiment, 10 leaf discs were inoculated and examined for each diploid or tetraploid.

In in vivo inoculation assays, five randomly chosen mature leaves on each clonal plant were inoculated by pipetting $100 \mu \mathrm{L}$ of a spore suspension $\left(2 \times 10^{5}\right.$ sporangia/mL $)$ onto the adaxial leaf side. The inoculated plants were enclosed in a plastic bag and placed in the growth room at $22{ }^{\circ} \mathrm{C}$ with a photoperiod of $12 \mathrm{~h}$ light $/ 12 \mathrm{~h}$ dark and a light intensity level of $\approx 100 \mu \mathrm{mol} \cdot \mathrm{m}^{-2} \cdot \mathrm{s}^{-1}$. Inoculated leaves were rated on a binary scale where $0=$ no visible sporulation (no disease) and $1=$ visible sporulation (diseased), and a disease incidence was calculated for each clonal plant. The experimental unit was a single containerized plant with five leaves inoculated per plant. Two in vivo inoculation experiments were conducted, and in each experiment, there were three replications for each diploid or tetraploid, and the replications were arranged in a completely randomized design.

Plasmopara obducens development in inoculated impatiens leaves was examined using a modified trypan blue staining protocol described by Vélez (2005). Inoculated leaf discs were collected at 1, 2, 3, 4, or 6 dpi and cleared in $50-\mathrm{mL}$ centrifuge tubes, first with $5 \mathrm{~mL}$ of the clearing solution A [acetic acid: absolute ethanol $(>99.5 \%)$ at $1: 3, \mathrm{v} / \mathrm{v}]$ on a shaker at about $80 \mathrm{rpm}$ overnight, and then with $5 \mathrm{~mL}$ of the clearing solution $\mathrm{B}$ (acetic acid: absolute ethanol: glycerol at $1: 5: 1, \mathrm{v} / \mathrm{v} / \mathrm{v})$ for at least $3 \mathrm{~h}$. Cleared leaf discs were stained in $5 \mathrm{~mL}$ of $0.01 \%$ trypan blue staining solution (trypan blue: lactic acid: phenol: distilled water $=0.003: 1: 1: 1$, $\mathrm{w} / \mathrm{v} / \mathrm{v} / \mathrm{v}$ ) overnight while they were shaken at about $80 \mathrm{rpm}$. Stained leaf discs were rinsed with autoclaved $60 \%$ glycerol. Finally, the stained leaf discs were placed on a clean slide with a drop of $60 \%$ glycerol and observed under a BX41 microscope (Olympus). For each time point, three leaf discs were sampled, cleared, stained, and observed for each diploid and tetraploid.

Statistical analysis. The software package SPSS v 22.0 (IBM SPSS Statistics for Windows, ver. 22.0; IBM Corp., Armonk, NY) was used for analysis of variance and mean separation. The significance of mean differences was tested using the Tukey's test at $P<0.05$.

\section{Results}

Polyploid induction, identification and confirmation. Impatiens seeds germinated readily under the conditions described above. Radicles emerged $4 \mathrm{~d}$ after sowing. At this stage the germinating seeds were subjected to colchicine treatment. Many of the treated seedlings stopped growth after extending cotyledons and failed to produce any true leaves. Presumably the growing point of these seedlings was killed by the colchicine treatment. These seedlings were not counted as surviving seedlings. Colchicine treatments reduced seedling survival rate dramatically. Even at $0.05 \%$ colchicine, seedling survival was only $16.7 \%$, reduced by as much as $83.7 \%$ (Table 1 ). By $\approx 2$ months after the treatment, a number of the treated seedlings looked different from the untreated ones, with larger and thicker leaves and thicker stems. All growing seedlings were analyzed for ploidy level, and 11 tetraploids were identified. Some mixoploids and octoploids were observed. This study focused on characterizing the solid tetraploids. Tetraploid induction rates for the four colchicine concentrations used $(0.05 \%$ to $2.0 \%)$ ranged from $0 \%$ to $5.8 \%$, and the resulted tetraploid induction efficiency varied between $0 \%$ and $1.5 \%$. The treatment with $0.05 \%$ colchicine for $2 \mathrm{~d}$ yielded the highest tetraploid induction rate $(5.8 \%)$ and the highest tetraploid induction efficiency $(1.5 \%)$.

The average nuclear DNA content of impatiens diploids was $3.94 \mathrm{pg} / 2 \mathrm{C}$. The average nuclear DNA content of tetraploids was $7.90 \mathrm{pg} / 2 \mathrm{C}$ (Table 2). All selected tetraploids displayed one peak in flow cytometry analysis, indicating that they were solid tetraploids (Fig. 1). Induced tetraploids had $2 n=4 x=32$ chromosomes whereas the diploids had $2 n=2 x=16$ chromosomes (Fig. 2).

Changes in morphology. The clonal plants of three tetraploids and three diploids were characterized to reveal morphological changes due to induced tetraploidy. All tetraploids showed significant morphological changes (Fig. 3). Tetraploids produced significantly larger, thicker leaves $(25.1 \%, 27.0 \%$, and $48.4 \%$ increase in leaf length, width, and thickness, respectively) and larger flowers $(57.5 \%$ increase in flower diameter) but produced fewer flowers per plant $(37.4 \%$ reduction). Significantly 
thicker shoots $(53.7 \%$ increase $)$ were observed in tetraploids, but the number of shoots produced per plant by tetraploids was $33.8 \%$ of that by diploids. Tetraploids took more days to flower $(9.7 \%$ increase). The stomata on tetraploid leaves were $\approx 36 \mu \mathrm{m}$ long and occurred at a density of 195.7 per $\mathrm{mm}^{2}$, that is, they were $50.0 \%$ longer but $42.2 \%$ fewer than those on diploid leaves (Fig. 4). Pollen grains of tetraploids were $67.9 \mu \mathrm{m}$ and showed $40.4 \%$ stainability. Compared with those of diploids, pollen grains of tetraploids were $28.6 \%$ larger and $32.2 \%$ more stainability (Fig. 5). No significant differences were observed among tetraploids or diploids $(P<0.05$, Table 2).

Changes in IDM resistance. In leaf disc assays, downy mildew white sporulation began to appear from the abaxial side of the inoculated leaf discs, 6 dpi for diploids and tetraploids. Sporulation became denser as the incubation progressed and eventually spread across the whole discs (Fig. 6). Evaluation of IDM severity on these leaf discs began $6 \mathrm{dpi}$ and repeated daily until $10 \mathrm{dpi}$. On diploid leaf discs, the IDM severity increased by $147.6 \%$ from 6 to $7 \mathrm{dpi}$ and then by $12.2 \%$ to $23.6 \%$ daily from 7 to $10 \mathrm{dpi}$. On tetraploid leaf discs, the IDM severity increased by $92.7 \%$ from 6 to $7 \mathrm{dpi}$ and then by $20.1 \%$ to $31.1 \%$ daily from 7 to $10 \mathrm{dpi}$. On average the IDM severity was significantly lower on tetraploid leaf discs than on diploid leaf discs, by $32.9 \%$ to $47.8 \% \quad 6$ through $10 \mathrm{dpi}$ (Table 3). No significant differences in IDM severity were observed among plants within the same ploidy level.

The sporangia density on diploid and tetraploid leaf discs increased as the incubation extended from 6 to $10 \mathrm{dpi}$. On tetraploid leaf discs, the sporangia density increased by an average of $387.1 \%$ between 6 and $8 \mathrm{dpi}$ and by $170.4 \%$ between 8 and 10 dpi. At 8 and 10 dpi, the sporangia density on tetraploid leaf discs was significantly lower (by $43.7 \%$ ) than that on diploids. No significant differences were observed among tetraploids or diploids (Table 4).

The development of $P$. obducens in the inoculated diploid and tetraploid leaf discs was examined by trypan blue staining at 1, 2, 3, 4, and 6 dpi. The pathogen seemed to go through a similar germination and development process inside both diploid and tetraploid leaves. Vesicles, hyphae, and haustoria were observed in leaf epidermal cells at $2 \mathrm{dpi}$; more hyphae and haustoria appeared in the leaf tissues from 3 to $6 \mathrm{dpi}$. By 6 dpi, monopodially branched sporangiophores began to emerge from the stomata on the abaxial side of the leaves and white sporulation became visible to the naked eyes (Fig. 7).

In the in vivo inoculation assays, IDM sporulation was not visible until $10 \mathrm{dpi}$ on diploid or tetraploid leaves, even though the leaves were inoculated with a spore suspension containing two times more spores than the spore suspension used in leaf disc assays. No significant differences in IDM incidence were observed among diploids or tetraploids

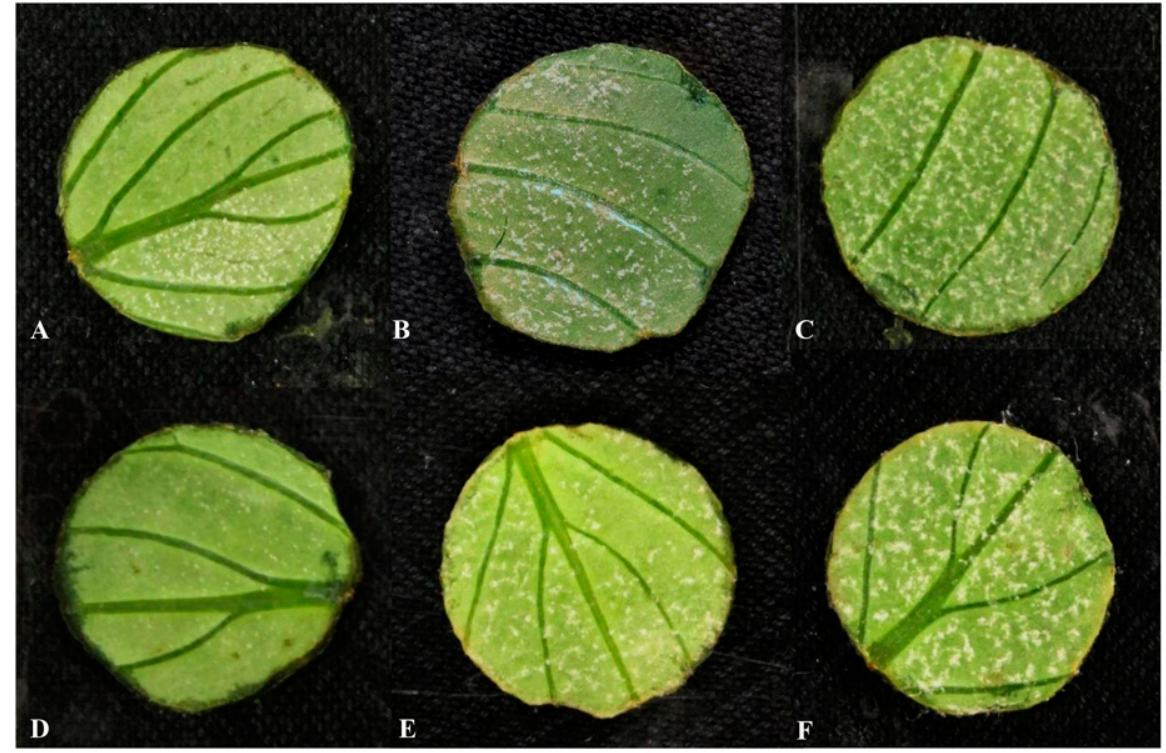

Fig. 6. Leaf discs of diploid and induced tetraploid impatiens used in leaf disc inoculation assays and showing white downy mildew sporulation on the abaxial surface of leaf discs. (A-C) Downy mildew progression on diploid leaf discs; and (D-F) downy mildew progression on tetraploid leaf discs.

Table 3. Differences between diploid (2x) and tetraploid (4x) plants of Impatiens walleriana cv. Super Elfin ${ }^{\circledR}$ Lipstick in downy mildew severity from 6 to $10 \mathrm{~d}$ post inoculation (dpi).

\begin{tabular}{lccccc}
\hline Lines & $6 \mathrm{dpi}$ & $7 \mathrm{dpi}$ & $8 \mathrm{dpi}$ & $9 \mathrm{dpi}$ & $10 \mathrm{dpi}$ \\
\hline $2 x \_1$ & $0.85 \pm 0.05 \mathrm{a}^{\mathrm{z}}$ & $2.01 \pm 0.07 \mathrm{a}$ & $2.51 \pm 0.07 \mathrm{a}$ & $2.79 \pm 0.08 \mathrm{a}$ & $3.18 \pm 0.09 \mathrm{a}$ \\
$2 x \_2$ & $0.81 \pm 0.09 \mathrm{a}$ & $2.05 \pm 0.12 \mathrm{a}$ & $2.51 \pm 0.09 \mathrm{a}$ & $2.89 \pm 0.07 \mathrm{a}$ & $3.24 \pm 0.08 \mathrm{a}$ \\
$2 x \_3$ & $0.80 \pm 0.06 \mathrm{a}$ & $2.04 \pm 0.06 \mathrm{a}$ & $2.50 \pm 0.07 \mathrm{a}$ & $2.90 \pm 0.07 \mathrm{a}$ & $3.21 \pm 0.08 \mathrm{a}$ \\
$4 x \_1$ & $0.55 \pm 0.05 \mathrm{~b}$ & $0.96 \pm 0.04 \mathrm{~b}$ & $1.34 \pm 0.05 \mathrm{~b}$ & $1.60 \pm 0.08 \mathrm{~b}$ & $1.98 \pm 0.06 \mathrm{~b}$ \\
$4 x \_2$ & $0.55 \pm 0.04 \mathrm{~b}$ & $1.10 \pm 0.06 \mathrm{~b}$ & $1.40 \pm 0.07 \mathrm{~b}$ & $1.71 \pm 0.08 \mathrm{~b}$ & $2.05 \pm 0.05 \mathrm{~b}$ \\
$4 x \_3$ & $0.55 \pm 0.04 \mathrm{~b}$ & $1.13 \pm 0.05 \mathrm{~b}$ & $1.44 \pm 0.04 \mathrm{~b}$ & $1.71 \pm 0.06 \mathrm{~b}$ & $2.04 \pm 0.07 \mathrm{~b}$ \\
\hline
\end{tabular}

${ }^{\mathrm{z}}$ Mean separation in columns by Tukey's method at $P<0.05$. Means were calculated from data from two independent experiments.

Downy mildew disease severity on each leaf disc was visually scored on a scale of 0 to 4 , with $0=$ no visible sporulation, and $1=1 \%$ to $25 \%, 2=26 \%$ to $50 \%, 3=51 \%$ to $75 \%$, and $4=76 \%$ to $100 \%$ of the leaf area with visible sporulation. Two experiments were conducted. In each experiment, at least four replications (40 leaf discs in four petri dishes) were examined at each point of time.

Table 4. Differences between diploid ( $2 x$ ) and tetraploid ( $4 x$ ) of Impatiens walleriana cv. Super Elfin ${ }^{\circledR}$ Lipstick in sporangia density of Plasmopara obducens $\left(10^{3} / \mathrm{cm}^{2}\right)$ on the abaxial side of leaf discs from 6 to $10 \mathrm{~d}$ postinoculation (dpi).

\begin{tabular}{llcl}
\hline Lines & $6 \mathrm{dpi}$ & $8 \mathrm{dpi}$ & $10 \mathrm{dpi}$ \\
\hline $2 x \_1$ & $3.34 \pm 0.61 \mathrm{NS}$ & $20.16 \pm 2.58 \mathrm{a}^{\mathrm{z}}$ & $55.26 \pm 6.17 \mathrm{a}$ \\
$2 x \_2$ & $3.17 \pm 0.61$ & $20.10 \pm 2.19 \mathrm{a}$ & $54.30 \pm 6.17 \mathrm{a}$ \\
$2 x \_3$ & $3.34 \pm 0.58$ & $19.99 \pm 1.86 \mathrm{a}$ & $53.22 \pm 3.96 \mathrm{a}$ \\
$4 x \_1$ & $2.04 \pm 0.34$ & $10.42 \pm 1.26 \mathrm{~b}$ & $30.63 \pm 2.50 \mathrm{~b}$ \\
$4 x \_2$ & $2.60 \pm 0.43$ & $12.34 \pm 1.33 \mathrm{~b}$ & $31.03 \pm 1.89 \mathrm{~b}$ \\
$4 x \_3$ & $2.32 \pm 0.43$ & $11.15 \pm 1.33 \mathrm{~b}$ & $30.00 \pm 2.81 \mathrm{~b}$ \\
\hline
\end{tabular}

${ }^{\mathrm{z}}$ Mean separation in columns by Tukey's method at $P<0.05$. Means were calculated from data from two independent experiments.

NS $=$ not significantly different

Two experiments were conducted and in each experiment, 10 leaf discs (replications) from a diploid or tetraploid were inoculated and incubated, and the spores borne on each leaf disc were collected and counted.

in any of the three evaluations (Table 5). However, tetraploid 4x_1 showed a significantly lower IDM incidence $(30.0 \%$ to $69.6 \%$ lower) at $10 \mathrm{dpi}$, and tetraploid $4 \mathrm{x} \_2$ had a significantly lower IDM incidence (by $21.9 \%$ to $34.5 \%$ ) at $11 \mathrm{dpi}$. Tetraploid $4 \mathrm{x} \_3$ showed a lower IDM incidence than the three diploids at all three time points (10-12 dpi). The differences between tetraploid $4 \mathrm{x} \_3$ and the three diploids in IDM incidence diminished between 10 and 12 dpi: $30 \%$ to $69.6 \%$ lower at $10 \mathrm{dpi}$, to $21.9 \%$ to $34.5 \%$ lower at $11 \mathrm{dpi}$, and to $13.0 \%$ lower at $12 \mathrm{dpi}$.

\section{Discussion}

Tetraploid induction, identification, and confirmation. Colchicine has been widely used to induce chromosome doubling. Tetraploid induction efficiency has been used as an important parameter to select colchicine treatments for tetraploid induction (Lehrer et al., 2008). In this study, the application of $0.05 \%$ colchicine yielded the highest tetraploid induction efficiency; thus, this concentration would be a good starting point for inducing additional impatiens tetraploids 

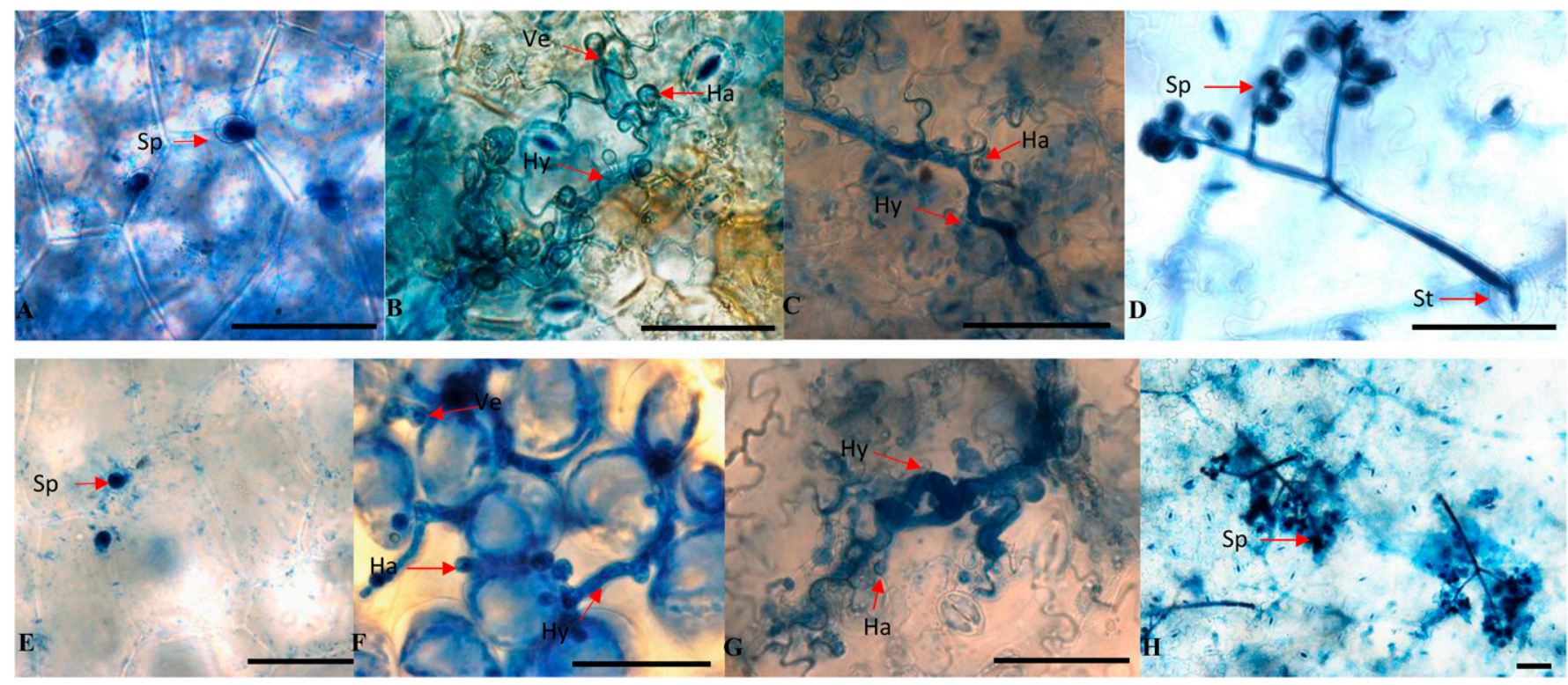

Fig. 7. Development of Plasmopara obducens (causal agent of impatiens downy mildew) inside 'Super Elfin ${ }^{\circledR}$ Lipstick' leaf discs from 1 to $6 \mathrm{~d}$ postinoculation (dpi) as revealed by trypan blue staining. (A) Sporangia inoculated on the adaxial surface of a diploid leaf disc 1 dpi. (B, C) Vesicle, hyphae, and haustoria observed inside a diploid leaf disc from 2 to 6 dpi. (D) Sporangiophore emerging from stomata on the abaxial surface of a diploid and sporangia borne on sporangiophore branches, 6 dpi. (E) Sporangia inoculated on the adaxial surface of tetraploid leaf discs 1 dpi. (F, G) Vesicle, hyphae, and haustoria observed inside tetraploid leaf discs from 2 to 6 dpi. (H) Sporangiophore emerging from stomata on the abaxial surface of tetraploid leaf discs, and sporangia borne on sporangiophore branches, 6 dpi. Bars $=50 \mu \mathrm{m} . \mathrm{Sp}=$ sporangia, $\mathrm{Ve}=$ vesicle, $\mathrm{Hy}=$ hypha, $\mathrm{Ha}=$ haustoria, and $\mathrm{St}=$ stomata.

Table 5. Differences between diploid $(2 x)$ and tetraploid (4x) of Impatiens walleriana cv. Super Elfin ${ }^{\circledR}$ Lipstick in downy mildew incidence from 10 to $12 \mathrm{~d}$ postinoculation (dpi) after in vivo inoculation of plants.

\begin{tabular}{llll}
\hline Lines & \multicolumn{1}{c}{$10 \mathrm{dpi}$} & $11 \mathrm{dpi}$ & $12 \mathrm{dpi}$ \\
\hline $2 x \_1$ & $0.17 \pm 0.03 \mathrm{ab}^{\mathrm{z}}$ & $0.73 \pm 0.04 \mathrm{ab}$ & $1.00 \pm 0.00 \mathrm{a}$ \\
$2 x \_2$ & $0.23 \pm 0.03 \mathrm{a}$ & $0.87 \pm 0.04 \mathrm{a}$ & $1.00 \pm 0.00 \mathrm{a}$ \\
$2 x \_3$ & $0.10 \pm 0.04 \mathrm{ab}$ & $0.73 \pm 0.04 \mathrm{ab}$ & $1.00 \pm 0.00 \mathrm{a}$ \\
$4 x \_1$ & $0.07 \pm 0.04 \mathrm{~b}$ & $0.70 \pm 0.04 \mathrm{ab}$ & $0.93 \pm 0.04 \mathrm{ab}$ \\
$4 x \_2$ & $0.17 \pm 0.03 \mathrm{ab}$ & $0.57 \pm 0.03 \mathrm{~b}$ & $0.90 \pm 0.04 \mathrm{ab}$ \\
$4 x \_3$ & $0.07 \pm 0.04 \mathrm{~b}$ & $0.57 \pm 0.06 \mathrm{~b}$ & $0.87 \pm 0.04 \mathrm{~b}$ \\
\hline
\end{tabular}

${ }^{\mathrm{z}}$ Mean separation in columns by Tukey's method at $P<0.05$. Means were calculated from data from two independent experiments.

Two independent inoculation experiments were conducted; in each experiment, there were three replications (three clonal plants) for each diploid or tetraploid, and on each clonal plant, five leaves were individually inoculated. Leaves with visible downy mildew sporulation were recorded as diseased and received " 1 " and leaves without visible sporulation were recorded as nondiseased and received " 0. "

in the future. In this study, the observed seedling survival rates were far below $50 \%$, suggesting that lower colchicine concentrations, shorter durations or both may be used in future tetraploid induction.

Morphological changes. Induced tetraploids produced thicker stems, larger leaves, and larger flowers, and larger stomata (but at lower densities). These results agreed with the morphological changes in New Guinea and Java impatiens tetraploids reported by Arisumi (1973b). The induced tetraploids produced larger flowers but fewer shoots and fewer flowers per plant in container trials. It will be interesting to determine if these morphological changes will affect the ornamental value and performance of induced tetraploids in the landscape.

Stomatal size and density have been used as an indicator of plant ploidy levels (Kadota and Niimi, 2002; Thao et al., 2003). As observed in this study, stomata on impatiens tetraploid leaves were significantly longer than those on diploid leaves, and the density of stomata on tetraploids was significantly lower than that on diploids. These differences may provide a simple way to identify putative tetraploids in future impatiens studies and breeding, in case ploidy analyzers are not available.

In this study, pollen grains from impatiens tetraploids showed $32.2 \%$ higher stainability than those from diploids. This differs from the results reported by Arisumi (1973b), where New Guinea and Java impatiens tetraploids had higher percentages of aborted pollen grains. Lower pollen stainabilities have been reported in many tetraploids in other species. Additional studies are needed to understand why the induced impatiens tetraploids in this study showed higher pollen stainabilities.

Changes in IDM resistance. In this study, all three tetraploids had significantly lower IDM disease severity from 6 to $10 \mathrm{dpi}$ and lower sporangia densities at 8 and $10 \mathrm{dpi}$, compared with diploids. A significant reduction of IDM disease incidence was also observed in one of the tetraploids (4x_3) in in vivo inoculation assays. Increased disease resistance has been reported in induced polyploids of other plant species; however, the mechanisms of such changes remain to be elucidated. Fort (2013) suggested that the increased resistance to pathogens in tetraploid $A$. thaliana accession C24 could be the result of changes in the expression of defense-related genes or changes in leaf architecture that may provide physical barriers against pathogen infection. Thick cuticle and trichomes can be important structures that guard against the penetration of pathogens (Archer and Cole, 1986; Levin, 1973) because stomata often serve as important entry sites for plant pathogens (Melotto et al., 2008). Ramos and Volin (1987) revealed that Lycopersicon spp. had lower incidence and severity of Xanthomonas campestris pv. vesicatoria when leaf stomatal closure was physiologically induced and stomatal opening was chemically suppressed, and that the stomatal density was positively correlated with the number of spot lesions produced after the infection. Potato (Solanum tuberosum) cultivars resistant to the late blight disease (Phytophthora infestans) had thicker cuticles, smaller stomata, lower stomatal densities, and larger trichomes compared with susceptible cultivars (Mahajan and Dhillon, 2003).

In this study, impatiens leaves were inoculated on the adaxial side where no stomata existed, thus it seems unlikely that the difference in IDM resistance between diploids and tetraploids resulted from the differences in stomatal size and density. As shown by our histological survey, the sporangiophores of $P$. obducens, the causal 
agent of IDM, emerged from stomata on the abaxial side at the end of the disease cycle. The question remains whether the much larger but much less dense stomata on the abaxial side of tetraploid leaves could reduce the emergence of $P$. obducens sporangiophores and reduce IDM disease severity and incidence. Future studies may focus on understanding the changes in leaf architecture and other anatomical structures (cuticle, trichome, etc.) as well as gene expression in these tetraploids.

\section{Literature Cited}

Archer, K. and A. Cole. 1986. Cuticle, cell-wall ultrastructure and disease resistance in maidenhair fern. New Phytol. 103:341-348.

Arisumi, T. 1973a. Chromosome numbers and interspecific hybrids among New Guinea Impatiens species. J. Hered. 64(2):77-79.

Arisumi, T. 1973b. Morphology and breeding behavior of colchicine-induced polyploid Impatiens spp. J. Amer. Soc. Hort. Sci. 98:599-601.

Bouvier, L., F.R. Fillon, and Y. Lespinasse. 1994. Oryzalin as an efficient agent for chromosome doubling of haploid apple shoots in vitro. Plant Breed 113:343-346.

Brown, M.V., J.N. Moore, R.W. McNew, and P. Fenn. 1999. Inheritance of downy mildew resistance in table grapes. J. Amer. Soc. Hort. Sci. 124:262-267.

Burdon, J. and D. Marshall. 1981. Interspecific and intraspecific diversity in the disease-response of glycine species to the leaf-rust fungus Phakopsora pachyrhizi. J. Ecol. 69:381-390.

Cao, Z., Z. Deng, and M. Mclaughlin. 2014. Interspecific genome size and chromosome number variation shed new light on species classification and evolution in Caladium. J. Amer. Soc. Hort. Sci. 139:449-459.
Doležel, J., J. Greilhuber, and J. Suda. 2007. Estimation of nuclear DNA content in plants using flow cytometry. Nat. Protoc. 2:2233-2244.

Ellwood, S., L. Kamphuis, T. Pfaff, R. Oliver, D. Samac, B.D. Foster-Hartness, B. Tivoli, C. Onfroy, A. Moussart, A.M. Villegas, J.C. Sillero, and D. Rubiales. 2007. Inoculation and growth with foliar pathogenic fungi. Medicago truncatula handbook. Noble Res. Inst., Ardmore, OK. 6 June 2016. <https:// www.noble.org/globalassets/docs/medicagohandbook/inoculation-growth-foliar-pathogenic. pdf>.

Fort, A. 2013. Genome dosage and parent of origin effects in a ploidy series of Arabidopsis thaliana. National Univ. Ireland, Galway, PhD Diss.

Hamill, S., M. Smith, and W. Dodd. 1992. In vitro induction of banana autotetraploids by colchicine treatment of micropropagated diploids. Austral. J. Bot. 40:887-896.

Heslop-Harrison, J. and Y. Heslop-Harrison. 1970. Evaluation of pollen viability by enzymatically induced fluorescence; intracellular hydrolysis of fluorescein diacetate. Stain Technol. 45:115-120.

Jones, K. and J.B. Smith. 1966. The cytogeography of Impatiens L. (Balsaminaceae). Kew Bull. 20(1):63-72.

Kadota, M. and Y. Niimi. 2002. In vitro induction of tetraploid plants from a diploid Japanese pear cultivar (Pyrus pyrifolia N. cv. Hosui). Plant Cell Rpt. 21:282-286.

Lehrer, J., M. Brand, and J. Lubell. 2008. Induction of tetraploidy in meristematically active seeds of Japanese barberry (Berberis thunbergii var. Atropurpurea) through exposure to colchicine and oryzalin. Scientia Hort. 119:67-71.

Levin, D.A. 1973. The role of trichomes in plant defense. Qrtly. Rev. Biol. 48:3-15.

Mahajan, M. and M. Dhillon. 2003. Relation of leaf epidermal characteristics with susceptibility and resistance of potato (Solanum tuberosum) to late blight disease (Phytophthora infestans). Indian J. Agr. Sci. 73:656-660.

Melotto, M., W. Underwood, and S. He. 2008. Role of stomata in plant innate immunity and foliar bacterial diseases. Annu. Rev. Phytopathol. 46:101-122.

Morgan, R.J. 2007. Impatiens: The vibrant world of busy Lizzies, balsams, and touch-me-nots. Timber Press, Portland, OR.

Oswald, B. and S. Nuismer. 2007. Neopolyploidy and pathogen resistance. Proc. Biol. Sci. 274:2393-2397.

Ramos, L. and R. Volin. 1987. Role of stomatal opening and frequency on infection of Lycopersicon spp. by Xanthomonas campestris pv. Vesicatori. Phytopathology 77:1311-1317.

Thao, N., K. Ureshino, I. Miyajima, Y. Ozaki, and H. Okubo. 2003. Induction of tetraploids in ornamental Alocasia through colchicine and oryzalin treatments. Plant Cell Tissue Organ Cult. 72:19-25.

Uchneat, M.S. 2007. Impatiens, p. 277-299. In: N.O. Anderson (ed.). Flower breeding and genetics. Issues, challenges and opportunities for the 21 st century. Springer, London.

United States Department of Agriculture/National Agricultural Statistics Service (USDA/NASS). 2006. Floriculture crops 2005 summary. 25 Sept. 2016. <http://usda.mannlib.cornell.edu/ usda/nass/FlorCrop//2000s/2006/FlorCrop-0426-2006.pdf>

United States Department of Agriculture/National Agricultural Statistics Service (USDA/NASS). 2016. Floriculture crops 2015 summary. 25 Sept. 2016. <http://usda.mannlib.cornell.edu/ usda/nass/FlorCrop//2010s/2016/FlorCrop-0426-2016.pdf>.

Vélez, H. 2005. Alternaria alternata mannitol metabolism in plant-pathogen interactions. PhD Diss.

Warfield, C.Y. 2011. Downy mildew of impatiens. 25 Sept. 2016. <http://ballpublishing.com/ GrowerTalks/ViewArticle.aspx?articleid=18921>. 